\title{
Experiences of Pain: A Longitudinal, Qualitative Study of Patients with Head and Neck Cancer Recently Treated with Radiotherapy
}

\author{
Anne Schaller, Britt Larsson, Mona Lindblad and Gunilla M Liedberg
}

\section{Linköping University Post Print}

\section{Tweet}

N.B.: When citing this work, cite the original article.

Original Publication:

Anne Schaller, Britt Larsson, Mona Lindblad and Gunilla M Liedberg, Experiences of Pain: A Longitudinal, Qualitative Study of Patients with Head and Neck Cancer Recently Treated with Radiotherapy, 2015, Pain Management Nursing, (16), 3, 336-345.

http://dx.doi.org/10.1016/i.pmn.2014.08.010

Copyright: WB Saunders http://www.elsevier.com/

Postprint available at: Linköping University Electronic Press

http://urn.kb.se/resolve?urn=urn:nbn:se:liu:diva-115363 


\section{Experiences of pain - a longitudinal qualitative study of patients}

\section{with head and neck cancer recently treated with radiotherapy}

Corresponding author:

Anne Schaller, RN, Pain and Rehabilitation Center, and Department of Medical and Health

Sciences, Linköping University, Linköping, Sweden

Email address: anne.schaller@liu.se

Telephone: +46101033970

Britt Larsson, associate professor, senior physician, Pain and Rehabilitation Center, and

Department of Medical and Health Sciences, Linköping University, Linköping, Sweden

Email address: britt.larsson@liu.se

Mona Lindblad, MSc, RN, Pain and Rehabilitation Center, and Department of Medical and Health Sciences, Linköping University, Linköping, Sweden

Email address: mona.lindblad@lio.se

Gunilla M Liedberg, associate professor, OT, Senior Lecturer, Department of Social and Welfare studies, Linköping University, Norrköping, Sweden

Email address: gunilla.liedberg@liu.se

The authors have no funding or conflicts of interest to disclose. 


\section{Abstract \\ Background}

It is not unusual for patients with Head and Neck Cancer (HNC) to suffer from both tumor- and treatment-related pain that is difficult to alleviate despite individualized pain management.

\section{Aim/ Design}

This qualitative study describes how HNC patients experience pain and how it influences HNC patients treated with radiotherapy (RT).

\section{Settings}

Qualitative semi-structured interviews were performed one month and six months after the completed RT. The interviews were semi-structured and addressed symptoms, moods, and suffering.

\section{Participants}

The study included $26 \mathrm{HNC}$ patients who had recently completed RT.

\section{Methods}

The interviews were analysed using manifest content analysis.

\section{Results}

The main category was: the HNC patients did not experience that the severe physical pain influenced the psychological suffering but pain only influenced the social life. Further, four categories were revealed: pain in the head and neck region, the overwhelming fatigue, the altered mood and preoccupied mind, and decreased participation and changed relations. Physical pain, psychological distress, and social withdrawal were prominent at both interviews and consequently their situation can be considered as chronic. Remarkably, there was no clear relationship expressed by the patients between pain and psychological load. 


\section{Conclusions}

The lack of clear relationships between pain and psychological distress may imply a biomedical view of pain or may reflect the difficult context i.e. patients facing a possibly life threating cancer. Thus, their situation might require a prioritization and negatively affect the possibility to identify the interaction between the different dimensions of pain.

The biopsychosocial model of chronic pain aims to understand the interaction between pain and psychosocial factors. Interventions aiming to make HNC patients to internalize the biopsychosocial model framework to manage pain could be useful and should be evaluated in future research. 


\section{Background}

Every year, about 650000 people are diagnosed with head and neck cancer (HNC) and about 350 000 people die of the disease globally (Argiris, et al., 2008). Risk-factors include tobacco smoking and alcohol consumption (Argiris, et al., 2008). The overall five-year survival rate varies between 23\% and 88\% depending on the type of HNC (Argiris, et al., 2008). Prevalence of pain in is common and about $80 \%$ reports of pain during cancer therapy (Epstein, et al., 2010). Earlier studies have already reported that providing pain relief for HNC patients is difficult (Elting, et al., 2008; Epstein, et al., 2009; Murphy, et al., 2009; Wong, et al., 2006).

The disease as well as the treatment, decrease wellbeing i e, patient's evaluation of his/her physical and mental health and satisfaction with their social situation (Saxena \& Orley, 1997). In a review of 35 studies examining the quality of life in HNC patients (Babin, et al., 2008) concluded that qualitative studies could improve the understanding of how to deal with the consequences of the disease. A combination of radiotherapy (RT), a standard treatment for HNC, and chemotherapy usually in combination with surgery is common, but often results in very painful side effects (Lalla, et al., 2008; Trotti, et al., 2003). RT induces inflammation of the mouth and mucous membranes of the throat - oral mucositis (OM). Although RT treatment has been combined with clinical guidelines such as symptomatic treatment and individualized pain medication including opioids (MASCC, 2013) to treat OM and tumor pain, most of these patients find little pain relief (Elting, et al., 2008; Ling \& Larsson, 2011). In oncology nursing the concept of total pain is used (Saunders, 1988) which includes the following: physical, psychological social and existential dimensions. 
A very common definition of pain is the International Association for the Study of Pain (IASP, 2013) defines pain as "an unpleasant sensory and emotional experience associated with actual or potential tissue damage, or described in terms of such damage". Social pain implies losing one's perceived roles in life such as losing a spouse or losing a job. Existential pain, according to Yalom, (1980) falls into four basic areas: loneliness, meaninglessness, death, and freedom. The presence of concomitant various dimensions of pain in the patients during the often difficult time period after RT has not been elucidated. Knowledge about these dimensions of pain and if and how they interact is essential in order to provide adequate care. The aim of this longitudinal qualitative study was to describe how HNC patients experience pain and how it influences those patients treated with RT.

\section{Patients and methods}

\section{Patients}

All HNC patients who went through RT and were referred to the Pain and Rehabilitation Centre at the University Hospital (Linköping, Sweden) were asked to participate in the study during the autumn 2011 until summer 2012. Of the 46 patients asked to participate, 26 agreed to participate. Table 1 outlines the socio-demographics and medical characteristics of the participants. No statistical differences concerning age and sex existed between participating patients and patients who declined to participate. Mean age in the participants was 64 years (standard deviation (SD) 10 years) and in the non-participants group was 65 years (SD 13 years); p-value 0.7. Among the participants $19(73 \%)$ were men, the corresponding figure among the non-participants was 12 (60\%); p-value 0.3 . 
Written and oral information was provided to participants, and the patients signed a written consent before the interviews. A numbered participant list was constructed and patients could not be identified on the tape or in the transcript. The regional Ethical Review Board in Linköping approved the study (2010-05-19).

\section{Interviews}

This qualitative study method uses interviews and an interview guide (Kvale, 1996; Patton, 2002). The patients were invited for two interviews. The first interview (26 patients) focused on capturing the patient's experience with pain and with waiting for the outcome of treatment. This interview was conducted one month after the patients completed their RT. We timed the interviews based on our clinical experience; many patients report that the weeks after completing RT are extremely painful. The second interview was conducted four to six months after the first interview. This time was chosen also based on our clinical experience patients' pain medication often is discontinued at this time. This arrangement made it possible to capture comprehensive experiences of patients' pain over time. All interviews were conducted by the first author (AS) either in the patient's home $(\mathrm{n}=12)$ or at the Pain and Rehabilitation Centre $(\mathrm{n}=14)$. At the second interview, 23 of the previous 26 patients participated. One patient had deceased and two declined to participate.

An interview guide was prepared to ensure that certain topics were discussed during the interview. The questions addressed the themes - existential, physical, psychological, and social pain - by focusing on symptoms, moods, family, suffering, and treatment. The formulation of the questions and when they were posed during the interview varied, depending on how the conversation developed. The opening question - "Can you describe your experiences since the 
start of the radiotherapy?" - gave rich information and often covered or initiated a discussion about many of the themes that were elicited using several follow-up questions: "What are your thoughts about what has happened to you?"; "In what way has the pain impacted on your life?"; "How do you feel emotionally?"; "What are your thoughts about the future?"; and "What does an ideal treatment look like?". At the end of the session, the interview guide was used as a checklist to guarantee that all the themes had been discussed. The interviews were audiotaped and varied in length from 11 minutes to 61 minutes. Mean duration for the interviews was at the first occasion 28 minutes (SD 12) and at the second occasion 31 minutes (SD11). One interview on the first occasion was conducted by telephone because of transportation difficulties.

\section{Data analysis}

Three interviews were transcribed verbatim by one of the authors (AS) and the rest by an experienced secretary. AS read each transcript and checked them against the tape. All interviews were organized in a computer program (Nvivo 9 (Edhlund, 2011)) designed for qualitative studies and used in the analysis procedure. The interviews were analyzed with qualitative content analysis as described by Elo and Kyngäs (2008) and Krippendorff (2004). All authors read, analyzed, and discussed the material to increase the reliability and trustworthiness of the material according to Krippendorff's protocol (Krippendorff, 2004).

Our analysis followed the steps outlined by Elo and Kyngäs (2008). First, each interview was read several times to form a general impression. Then, each interview was read to identify meaning units. Next, a meaning unit, consisting of a sentence, several sentences, or a paragraph, were collected into codes. The codes were then sorted into subcategories. These subcategories were used to develop categories, and the main category was created. Finally, the internal 
consistency and external plausibility of the category system was tested for its completeness by ensuring that the text content was only recovered in one category (Malterud, 2001).

Quotations are used in the text to allow the reader to evaluate the results and were adapted in written language according to Kvale (1996) to avoid stigmatization. In the Results section, brackets [ ] are used to indicate implied words.

\title{
Results
}

A main category (table 2) - the HNC patients did not experience that the severe physical pain influenced the psychological suffering but pain only influenced the social life - is based on the following four categories: pain in the head and neck region, the overwhelming fatigue, the altered mood and preoccupied mind, decreased participation and changed relations.

\section{The HNC patients did not experience that the severe physical pain influenced the psychological suffering but pain only influenced the social life}

\section{Pain in the head and neck region}

\begin{abstract}
Almost all of the patients noted pain located in the oral cavity and pharynx. Sores and blisters especially on the tongue but also in the oral cavity and on the palate were described as painful: "It burns on the tongue and it stings in the throat and ... yes, burns in the whole mouth. It's like a sea of fire in the mouth" (71-year-old woman).
\end{abstract}

Furthermore, pain when swallowing was common and was described as stinging, burning, scorched, and a tonsillitis feeling. One 53-year-old man described swallowing as feeling "like a razor blade drawn up and down the throat". Other pain sites were identified: radiating pain in the ear, cheekbones, teeth, salivary glands, nose (internal sores), and head (in the form of 
headaches). Four to six months later, about half of the patients still painful and aching blisters and sores in their oral cavity, pain in the pharynx, and persistent radiating pain in the ear.

Nearly all patients used pain medication regularly. More than half mentioned that they used opioid medications and some reported good efficacy. One 65-year-old man stated the following: "I used morphine ... and paracetamol ... the pain was relieved ... it's hard to say though ... because you don't know how difficult the pain would have been if you didn't have had any pain medication". Four to six months later, opioid medications were still used by some patients and several patients still reported pain, above all, in their oral cavity and pharynx. However, several patients reported using opioid medication only when they experienced pain at its worst. In contrast, a few patients experienced no pain relief despite how much analgesic they were prescribed. Furthermore, a few of the patients experienced constipation, nausea, dizziness, micturition disturbance which may be side effects of opioid treatment. Further, a few patients reported withdrawal effects related to opioid treatments such as palpitations and sensations of pins and needles in arms and legs. One 51-year-old female patient explained her dilemma when trying to decide how to control her pain and the side effects of her medications: “. . . it's like if you use that medication, then you have to take the other for the stomach ... and if you take that one...".

\section{The overwhelming fatigue}

At the first as well as at the second interview, a majority of patients identified fatigue as impacting their state. They noted a feeling of not being able to do anything and that it did not help to rest. Furthermore, the patients declared that their sleep had been affected, some with reduced sleep and some who slept significantly more than usual: "I slept perhaps about 16 hours 
a day actually .. . I was extremely tired all the time . . but I couldn't get any good sleep" (56year-old man).

The loss of spark and energy led to consequences for their physical activity, and merely moving was experienced as very strenuous. Fatigue led to a passive life style. For example, some patients reported that they no longer bothered with the usual chores or that it took longer to do chores in general: "The tiredness makes you feel a certain listlessness in doing things . . . no, you don't deal with things as you normally would have done. . . it's the tiredness" (68-year-old man).

Many of the patients still experienced tiredness four to six months later. Sleep disturbances were also mentioned, although not to the same degree. The feeling of lost strength and a pronounced debility persisted for many of the patients, and reasons for fatigue commonly mentioned were impaired food intake, weight loss, pain, and morphine treatment.

\section{The altered mood and preoccupied mind}

Almost all reported alterations in moods. Tearfulness, depression, anxiety, anger, and irritation were feelings not experienced previously, and these feelings remained four to six months later. A 71-year-old woman described these feelings: "Yes, I do get very sad and I cry . . yes, I become depressed ... I think I get a little evil . . I think I am experienced as bothersome”. Because of changes in mood, some patients expressed a need to withdrawal.

Anxiety of survival and concern regarding RT risks affected the patients' mood. In both interviews, the patients mentioned both positive and negative encounters with health care and how this affected them. A few patients, because they felt their reception into the health care system had been inconsiderate, had feelings of mistrust. The importance of adequate medical 
information was highlighted. According to the patients who received what they considered adequate information, this information had a calming and positive effect. "It is a fact that the information is ... the most important thing .... it soothes, yes it calms everything" (69-year-old man).

In addition, it was also emphasized that contact and information was needed also after RT was completed in order to improve their state: "When the radiotherapy started and everything . . my experience was that I received support from many staff ... after the final radiation and the final chemical treatment was done ... then everyone disappeared" (52-year-old woman). According to some patients, easily accessible contact with a nurse would improve their situation: "Perhaps some better follow-ups. That they don't let you go . . perhaps some more contacts . . you get your appointments but it's rather long time between them ... three months for someone with problems is an extremely long time I have to say" (45-year-old man).

Some patients reported a depressed mood caused by decreased beard growth, hair loss, facial swelling, and surgery affecting appearance. One 58 -year-old woman was distressed by how surgery changed her appearance: "The worst thing was to see myself in the mirror the first time after surgery. I feel people's reaction [to my appearance], so I avoid being among people".

During the first interview, more than half of the patients expressed that the diagnosis itself caused them to reflect about death. A 58-year-old woman stated it this way: "You are afraid that it's not ... that they haven't removed everything at the surgery ... it will not be a success . . that I will die ... I don't want that". The patients were preoccupied that the cancer relapsed or did not diminish as expected. A 66-year-old woman noted that living with these uncertainties was stressful: “. . . but I think it's the feeling of uncertainty ... what will happen? You don't dare to 
plan anything ... you walk around pondering if you are healthy or not . . what happens actually [in my body]?"

During the second interview, almost all the patients mentioned that they still were preoccupied with cancer, death, and the efficacy of the treatment. For example, a 68-year-old man reported that his psychological state was vulnerable after completing RT: "When you have gone through this ... there will be a lot of thoughts in your head and if you don't have someone to discuss this with . . then you walk around ruminating and pondering”.

The patients expressed high confidence in the treatment, as the treatment was their only option. Many participants emphasized that positive thinking meant continued belief that the treatment would conquer the illness. A man in his late sixties told of his attempt to remain positive: "I made up my mind to fix this ... with the help from my physician, my will, and my good spirits ... I will fix this".

Feelings of unfairness were apparent as several patients expressed that such a disease happens to others and these concerns remained at the second interview. One 65-year-old man described his feelings about fairness: "You think that it perhaps is a little bit unfair . . if you may have an opinion”. Furthermore, patients experienced a sense of guilt because of their on-going or previous tobacco smoking. In addition, several patients felt guilty about complaining as they often felt other patients might even have a worse situation.

Nearly all patients reflected about the meaning of life and mentioned the importance of being healthy. This reflection also included the health of family and friends and being able to gather with their families. At the second interview, the significance of the meaning of life was still 
dominated by health: "The family is important . . . and that I may feel as I am now and not getting worse ... that you are able to keep the little health you got now" (58-year-old woman).

Their perspective of life had changed and life was not taken for granted. Furthermore, matters previously of importance had declined in significance: "Why such retirement savings; I might not live when I retire. I have cancer and I am not sure to survive . . so I decided to use my money here and now" (52-year-old woman).

Many patients emphasized the importance of believing in a future, however uncertain, as necessary in order to manage the treatment. On the contrary, a few patients expressed that they did not think about the future. These patients had a shorter time perspective with respect to planning and expressed a need to live one day at a time. At the second interview, several patients were more hopeful and expressed a yearning for the future as they talked about upcoming seasons and holidays, family gatherings, their children, and grandchildren. One 56-year-old man declared: "I want to go back working again and continue to do carpentry at our house ... and go for a walk with the dogs and doing such things . . to get back to my previous life situation”.

\section{Decreased participation and changed relations}

In both the first and second interview, more than half of the patients experienced a changed social life. Eating difficulties resulted in a withdrawal in socialization. Patients often avoided eating with others because they found chewing difficult, they felt they ate too slowly, and could not keep their mouth closed while chewing. Furthermore, their altered physical condition influenced their eating: "When I move the food in my mouth, I did not have anything to move it with really. The tongue's removed except twenty-five per cent of it" (50-year-old man). Furthermore, having no palate, an effect of surgery, influenced food intake as liquids passed through the nose: "I must use my fingers 
while eating [support with fingers to avoid the food to fall out of the mouth] . . and to have something to dry my corners of my mouth, since the palate is not tight yet so I get it running down through my nose ... its situated by the nose, leftovers and viscous saliva and the ..." (67-year-old man).

More than half of the patients experienced lack of appetite because of no hunger or that they could not stand the sight of food because of nausea, a situation that diminished their desire for social contacts. The lack of appetite and lack of taste were mentioned as often during the second interview as the first. Furthermore, patients emphasized the time aspect as meals can take hours to complete, which made socialization with others more difficult: "It can take on hour to eat one potato” (71-year-old woman).

As a consequence of OM, many patients experienced speech difficulties and voice changes. In addition, pain, swelling of the mouth or hoarseness and surgery led to a murmured and slurred talk. These difficulties led to a withdrawal from social interaction. In the second interview, some reported persistent problems caused by hoarseness or that it was strenuous to talk, and silence and a perception of isolation followed: "You may think when I talk . . as I may be drunk . . I slur my words . . you don't talk if you don't have to" (79-year-old man).

During both interviews, patients noted that they relieved feelings of isolation and withdrawal by receiving support from relatives. A few experienced improved contact with their relatives by developing a closer and more frequent contact. A few patients mentioned that they had to deal with worried relatives. Patients expressed a concern for making their illness less of a burden for their families: "Then there have been concerns amongst them all the time that I have tried to deal with ... and then you have had to comfort as well, both me and my wife" (56-year-old man). 


\section{Discussion}

In this study, the majority of patients were either experiencing or had previously experienced physical pain due to the cancer or to treatment in spite of individualized opioid treatment that was mostly combined with adjuvants such as non-steroidal anti-inflammatory drugs. The results agree with several studies reporting function-related mucositis pain, tumor pain, and breakthrough pain as very common in cancer patients (Bhatnagar, et al., 2010; Epstein, et al., 2010; Pauloski, et al., 2011). In two studies, as in ours, this pain was clearly and primarily linked to RT-induced mucositis (Cheng \& Lee, 2011; Rose-Ped, et al., 2002).

Fatigue has been reported to affect up to $70 \%$ of cancer patients undergoing chemotherapy and radiotherapy (Blesch, et al., 1991; Smets, et al., 1993). In our study, fatigue, weakness, and sleep disturbances were troublesome symptoms after receiving a diagnosis. One review found that fatigue, loss of appetite, and physical pain reduced HNC patients' quality of life (Montazeri, 2009). After diagnosis, those interviewed in our study underwent an intensive period of demanding treatment, which, for many, also entailed long and tiring daily travel to and from a treatment facility. Support by the health care system for physical activity could be helpful for tired and weak patients, as it has been shown that inactivity induces muscular catabolism thereby prolonging fatigue (Courneya, et al., 2000). Furthermore, at least one meta-analysis (Velthuis, et al., 2010) has shown that regular aerobic exercise resulted in a moderate improvement in cancerrelated fatigue.

During both interviews, almost all patients reported shifts in mood. Depression and fatigue have previously (Cheng \& Lee, 2011; Kohda, et al., 2005; Sawada, et al., 2012) been reported during the middle, end, or after the conclusion of RT for HNC patients. In addition, the patients 
expressed anxiety that the cancer would relapse or not diminish. This uncertainty was experienced as a source of worry in both interviews. In fact, worry about recurrence is common for HNC patients who have been declared cancer-free after recently undergone treatment (Rogers, et al., 2010).

The patients were still mentally preoccupied with the highly strenuous RT they had undergone. Some patients reported that the health care service provided erroneous information or information about rapid improvements that did not occur. Additionally, many patients were also waiting for treatment evaluations, a delay that likely had heightened their feelings of uncertainty and fear of death. From the interviews we, according to the method applied, identified four categories and one of these concerned HNC and its treatment. However, it is important to point out that this category also is the context and main cause of their situation which may explain why $\mathrm{HNC}$ has a prominent role in the reports of the patients."

Some patients expressed feelings of guilt and these were clearly linked to prior or current tobacco smoking. The majority of patients were either smokers or had previously been smokers. The explanation as to why so few patients mentioned or commented on feelings of guilt in relation to tobacco use may be that they felt this link to be too painful even to mention. In addition, the calming effect of smoking may have been too great. The pain-relieving effect of tobacco smoking has been suggested in one study (Logan, et al., 2010), and such effects may have contributed to the fact that almost half of the patient group were tobacco smokers.

The low tendency to communicate feelings of guilt corresponds to findings of a study of 162 cancer patients in which only seven (4\%) mentioned guilt (Morita, et al., 2000). However, 
feelings of guilt in relation to themselves and relatives were expressed indirectly in an interview study on patients suffering from an advanced stage of cancer (Blinderman \& Cherny, 2005).

The patients in this study also expressed a sense of unfairness in as much as they felt they had suffered a harsh blow despite the fact that they had lived good, decent lives. To be hit hard by illness despite this view of themselves gave rise to feelings of unfairness and a lack of meaning. This sense of unfairness, which also includes a sense of failure and inadequacy, in this situation has also been described by Bruce et al. (2011) and Yalom (1980).

Attempts to locate positive emotions in a negative experience in order to endure a difficult situation have been described by Folkman (1997), Strang (2007), and Yalom (1980). The interviewed patients, who were in the treatment phase of their illness, often gave direct expression to a feeling of meaninglessness, but also expressed a strong ambition to find meaning in life through positive thinking about the future. A strong desire to live and to fight against death and negative thoughts and an intense desire to be normal and healthy were also observed in women recently-diagnosed with breast cancer (Landmark, et al., 2001).

At the completion of the treatment, daily routines such as long travel times and ceased medical appointments at the health care service coincided with feelings of emptiness and abandonment. At both interviews, the majority of patients found themselves in a situation in which the search for meaning was central. During the second interview, it was reported that the majority of patients had succeeded quite well in finding meaning and hope by thinking about and planning for the future (e.g., planning for holidays, travel, and their return to work). Spending time with others - particularly with family - also provided a great deal of meaning for many. 
Furthermore, it became apparent that many patients re-evaluated and reprioritized what they considered most important in life. Patient' relationships with their relatives improved and the value of material things declined, a development that was also noted in earlier studies carried out primarily with palliative and terminal patients (Adelbratt \& Strang, 2000; McGrath, 2003). Yalom (1980) concludes that re-evaluation and reprioritization can be viewed as a way of gaining something positive from an external threat to life. This existential perspective might also apply to cancer diagnosis and demanding treatments. In our study, the desire to strengthen relationships could be seen as an expression of increased basic joy of life for the patients during their treatment phase.

A few patients felt certain that they, in particular, could be saved by the efforts of medical staff, a belief that can also be interpreted as a defence mechanism against the fear of death. Yalom (1980) calls this defence mechanism the "ultimate rescuer". The clearly observed fear of death, however, remained largely unchanged in the second interview despite the fact that state and situation to a certain extent was reported to have improved in the majority of interviewees.

A few patients had experienced feelings of mistrust and offence in their dealings with the health care system as a result of inconsiderate behavior on the part of caregivers. To be believed and listened to and to feel secure and to receive personalised care were all mentioned as important in an interview study conducted six weeks to nine months after HNC diagnosis (Björklund, et al., 2009)

Some patients expressed feelings of loneliness and isolation perhaps partly related to the personal and social circumstances that led to a need for extensive contact with health care service after completing treatment. These feelings might be similar to the abandonment previously described 
(Chapple, et al., 2006; Engel, 1980; Stajduhar, et al., 2010) by palliative and terminally ill patients when health care was made less available. To our knowledge, such a situation has never been reported for $\mathrm{HNC}$ patients in the treatment phase.

Some patients reported depressed moods caused by physical alterations related to their treatment (i.e., decreased beard growth, hair loss, facial swelling, and changes in appearance caused by surgery). This reaction is in line with a review (Babin, et al., 2008) that found that changes to a patient's appearance after surgery resulted in decreased quality of life. Some patients in our study also expressed the need to withdrawal as a consequence of a depressed mood that curtailed their social life.

Undoubtedly, the patients communicated physical pain they experienced in their daily life. Remarkably, however, their description of pain was not colored by psychological load such as tearfulness, depressed mood, anxiety, anger, and irritation, all reactions that were commonly.

Thus, there was no clear relationship expressed by the patients between pain and psychological load. The patients described the different aspects of pain (i.e., physical, psychological, and social pain) during both interviews and consequently their situation can be considered chronic.

Biomedicine's historical concept of chronic pain as merely the organic basis requiring a specific bio-medical intervention has increasingly given way to treating chronic pain as a biopsychosocial phenomenon requiring integrated multidisciplinary treatment. Chronic pain is a complex experience influenced as much by biological factors as by patients' social and cultural environment, beliefs, expectations, attitudes, and the meanings they ascribe to their pain. This biopsychosocial (BPS) model (Gatchel, et al., 2007) aims to understand the interaction between biological state and psychosocial factors. However, such interactions were not revealed in the 
interviews except for the previously mentioned experiences of depressed mood related to physical alterations and social withdrawal. The interviewed seemed to have a biomedical mindset and to be preoccupied with the severe situation of having a cancer diagnosis and pain. This finding is in line with earlier research reporting that patients with chronic low back pain were to a great extent biomechanically oriented regarding their pain (Allegretti, et al., 2010). An alternative interpretation is that the context i.e. facing a possibly life threatening $\mathrm{HNC}$ and participating in strenuous RT, required a prioritization and/or negatively affected the possibility to identify the interaction between the different dimensions of pain i.e., physical and emotional“".

Studies of reattribution interventions, although not in patients with cancer and chronic pain, have found short-term psychological improvements (Morriss, et al., 1999). Interventions aiming to make HNC patients internalise the BPS framework to manage pain should be evaluated in future research. The complexity of the BPS model may keep patients from embracing the model, and sufficient support from health care providers has to be carefully considered in such interventions.

According to Gatchel et al. (2007), feelings of emotional distress as well as feelings of hope, often topics included in the existential questions, and also common among the patients of this study, can be considered part of the BPS model. However, some aspects of a pain situation often referred to as existential e.g., thoughts of meaninglessness and death, which also were prominent among our patients, are not explicitly part of the BPS model. Responsiveness to existential pain and counselling from health care providers would probably benefit the patients.

\section{Method discussion}

Interviews are well suited for capturing patients' experiences and thoughts in a specific area (Kvale, 1996). An interview guide was used to ensure that certain areas were discussed. A 
standard opening question was used; however, as the patients themselves directed the course of the interview, no two interviews were alike. Using a non-standardized approach in interviews makes it easier to probe and to draw out more substantial answers from patients (Kvale, 1996; Patton, 2002). It can be argued that lack of links between physical and emotional dimensions of pain in the reports of the patients could have been due to that the questions and follow up questions did not make the link between these dimensions. However, making such a link may have introduced elements of a certain model of pain (BPS) and biased the reports of the patients and hereby reduced the opportunity to use the results of the study when designing future nonpharmacological interventions. All interviews were performed by one of the authors, which could be seen as a strength as it facilitated a similar approach in the interview situation. Conducting interviews with each patient on two separate occasions over a six-month period provided the opportunity to describe the findings over time. Although the interviewers were employed by the Pain Unit, they were not involved in these specific patients' treatment, so the patients' treatment was not affected by these interviews. Furthermore, the credibility of the results was validated through each author's reading and separate analysis before comparing and confirming the categories.

Recruiting a consecutive, small sample with different cancer diagnoses generally with an uncertain prognosis and with different surgical treatments limits the transferability of the findings to a larger population of patients. In addition, as this study only included patients from one pain clinic, the ability to transfer these findings to other pain units is limited.

\section{Conclusion}

Physical pain, psychological distress, and social withdrawal were prominent in the patients. The patients did not express any clear relationships between pain and psychological distress, a finding 
that may imply a biomedical view of pain or may reflect the difficult context i.e. patients facing a possibly life threating cancer necessitating a prioritization and/or negatively affected the possibility to identify the interaction between the different dimensions of pain. Whatever reason for the lack of identifying the relationships between the dimensions of pain may reduce the possibility to cope and handle a severe situation. We think that it is time to introduce a modern and increasingly accepted model for chronic pain, the BPS model, in the cancer-related pain management. It is then important that the BPS model carefully consider the context with a possible life threating condition and strenuous pharmacological and radio therapeutic treatments. Future research should evaluate interventions aimed to help HNC patients internalise the BPS framework to manage pain. In addition, our study demonstrates that the patient group suffered from existential pain as early as in the treatment phase. The patient's overall pain situation should be considered from diagnosis and onwards. “

\section{Conflict of Interest}

We have none financial relationship to declare and we have full control of all primary data. We agree to allow the journal to review the data if requested. 


\section{References}

Adelbratt, S., \& Strang, P. (2000). Death anxiety in brain tumour patients and their spouses. Palliative Medicine, 14, 499-507.

Allegretti, A., Borkan, J., Reis, S., \& Griffiths, F. (2010). Paired interviews of shared experiences around chronic low back pain: classic mismatch between patients and their doctors. Family practice, 27, 676-683.

Argiris, A., Karamouzis, M. V., Raben, D., \& Ferris, R. L. (2008). Head and neck cancer. Lancet, 371, 1695-1709.

Babin, E., Sigston, E., Hitier, M., Dehesdin, D., Marie, J. P., \& Choussy, O. (2008). Quality of life in head and neck cancers patients: predictive factors, functional and psychosocial outcome. European archives of oto-rhino-laryngology : official journal of the European Federation of Oto-Rhino-Laryngological Societies, 265, 265-270.

Bhatnagar, S., Upadhyay, S., \& Mishra, S. (2010). Prevalence and characteristics of breakthrough pain in patients with head and neck cancer: a cross-sectional study. Journal of palliative medicine, 13, 291-295.

Björklund, M., Sarvimäki, A., \& Berg, A. (2009). Health promoting contacts as encountered by individuals with head and neck cancer. Journal of Nursing \& Healthcare of Chronic Illnesses, 1, 261-268.

Blesch, K. S., Paice, J. A., Wickham, R., Harte, N., Schnoor, D. K., Purl, S., Rehwalt, M., Kopp, P. L., Manson, S., Coveny, S. B., \& et al. (1991). Correlates of fatigue in people with breast or lung cancer. Oncology Nursing Forum, 18, 81-87. 
Blinderman, C. D., \& Cherny, N. I. (2005). Existential issues do not necessarily result in existential suffering: lessons from cancer patients in Israel. Palliative Medicine, 19, 371380.

Bruce, A., Schreiber, R., Petrovskaya, O., \& Boston, P. (2011). Longing for ground in a ground(less) world: a qualitative inquiry of existential suffering. BMC nursing, 10, 2.

Chapple, A., Ziebland, S., \& McPherson, A. (2006). The specialist palliative care nurse: a qualitative study of the patients' perspective. International journal of nursing studies, 43 , 1011-1022.

Cheng, K. K., \& Lee, D. T. (2011). Effects of pain, fatigue, insomnia, and mood disturbance on functional status and quality of life of elderly patients with cancer. Critical reviews in oncology/hematology, 78, 127-137.

Courneya, K. S., Keats, M. R., \& Turner, A. R. (2000). Physical exercise and quality of life in cancer patients following high dose chemotherapy and autologous bone marrow transplantation. Psycho-oncology, 9, 127-136.

Edhlund, B. M. (2011). Nvivo 9 essentials : your guide to the world's most powerful qualitative data analysis software. Stallarholmen, Sweden: Form \& Kunskap AB.

Elo, S., \& Kyngas, H. (2008). The qualitative content analysis process. Journal of advanced nursing, 62, 107-115.

Elting, L. S., Keefe, D. M., Sonis, S. T., Garden, A. S., Spijkervet, F. K., Barasch, A., Tishler, R. B., Canty, T. P., Kudrimoti, M. K., \& Vera-Llonch, M. (2008). Patient-reported measurements of oral mucositis in head and neck cancer patients treated with radiotherapy with or without chemotherapy: demonstration of increased frequency, severity, resistance to palliation, and impact on quality of life. Cancer, 113, 2704-2713. 
Engel, G. L. (1980). The clinical application of the biopsychosocial model. The American journal of psychiatry, 137, 535-544.

Epstein, J. B., Hong, C., Logan, R. M., Barasch, A., Gordon, S. M., Oberle-Edwards, L., McGuire, D., Napenas, J. J., Elting, L. S., Spijkervet, F. K., \& Brennan, M. T. (2010). A systematic review of orofacial pain in patients receiving cancer therapy. Supportive care in cancer, 18, 1023-1031.

Epstein, J. B., Wilkie, D. J., Fischer, D. J., Kim, Y. O., \& Villines, D. (2009). Neuropathic and nociceptive pain in head and neck cancer patients receiving radiation therapy. Head \& neck oncology, 1, 26.

Folkman, S. (1997). Positive psychological states and coping with severe stress. Social science \& medicine, 45, 1207-1221.

Gatchel, R. J., Peng, Y. B., Peters, M. L., Fuchs, P. N., \& Turk, D. C. (2007). The biopsychosocial approach to chronic pain: scientific advances and future directions. Psychological bulletin, 133, 581-624.

IASP. (2013). International Association for the Study of Pain, IASP.I.A.f.t.S.o.P. Pain definitions. .

Kohda, R., Otsubo, T., Kuwakado, Y., Tanaka, K., Kitahara, T., Yoshimura, K., \& Mimura, M. (2005). Prospective studies on mental status and quality of life in patients with head and neck cancer treated by radiation. Psycho-oncology, 14, 331-336.

Krippendorff, K. (2004). Content analysis : an introduction to its methodology. Thousand Oaks, Calif.: Sage.

Kvale, S. (1996). Interviews : an introduction to qualitative research interviewing. Thousand Oaks, Calif.: Sage Publications. 
Lalla, R. V., Sonis, S. T., \& Peterson, D. E. (2008). Management of oral mucositis in patients who have cancer. Dental Clinics of North America, 52, 61-77, viii.

Landmark, B. T., Strandmark, M., \& Wahl, A. K. (2001). Living with newly diagnosed breast cancer--the meaning of existential issues. A qualitative study of 10 women with newly diagnosed breast cancer, based on grounded theory. Cancer nursing, 24, 220-226.

Ling, I. S., \& Larsson, B. (2011). Individualized pharmacological treatment of oral mucositis pain in patients with head and neck cancer receiving radiotherapy. Supportive care in cancer : official journal of the Multinational Association of Supportive Care in Cancer, 19, 1343-1350.

Logan, H. L., Fillingim, R. B., Bartoshuk, L. M., Sandow, P., Tomar, S. L., Werning, J. W., \& Mendenhall, W. M. (2010). Smoking status and pain level among head and neck cancer patients. The journal of pain : official journal of the American Pain Society, 11, 528-534.

Malterud, K. (2001). The art and science of clinical knowledge: evidence beyond measures and numbers. Lancet, 358, 397-400.

MASCC, M. A. o. S. C. i. C. (2013). MASCC/ISOO Mucositis Guidelines. In (Vol. 10/1 2014).

McGrath, P. (2003). Spiritual pain: a comparison of findings from survivors and hospice patients. The American journal of hospice \& palliative care, 20, 23-33.

Montazeri, A. (2009). Quality of life data as prognostic indicators of survival in cancer patients: an overview of the literature from 1982 to 2008. Health and quality of life outcomes, 7, 102.

Morita, T., Tsunoda, J., Inoue, S., \& Chihara, S. (2000). An exploratory factor analysis of existential suffering in Japanese terminally ill cancer patients. Psycho-oncology, 9, 164168. 
Morriss, R. K., Gask, L., Ronalds, C., Downes-Grainger, E., Thompson, H., \& Goldberg, D. (1999). Clinical and patient satisfaction outcomes of a new treatment for somatized mental disorder taught to general practitioners. The British journal of general practice : the journal of the Royal College of General Practitioners, 49, 263-267.

Murphy, B. A., Beaumont, J. L., Isitt, J., Garden, A. S., Gwede, C. K., Trotti, A. M., Meredith, R. F., Epstein, J. B., Le, Q. T., Brizel, D. M., Bellm, L. A., Wells, N., \& Cella, D. (2009). Mucositis-related morbidity and resource utilization in head and neck cancer patients receiving radiation therapy with or without chemotherapy. Journal of pain and symptom management, 38, 522-532.

Patton, M. Q. (2002). Qualitative research and evaluation methods. Thousand Oaks, Calif.: Sage Publications.

Pauloski, B. R., Rademaker, A. W., Logemann, J. A., Lundy, D., Bernstein, M., McBreen, C., Santa, D., Campanelli, A., Kelchner, L., Klaben, B., \& Discekici-Harris, M. (2011). Relation of mucous membrane alterations to oral intake during the first year after treatment for head and neck cancer. Head \& neck, 33, 774-779.

Rogers, S. N., Scott, B., Lowe, D., Ozakinci, G., \& Humphris, G. M. (2010). Fear of recurrence following head and neck cancer in the outpatient clinic. European archives of oto-rhinolaryngology : official journal of the European Federation of Oto-Rhino-Laryngological Societies, 267, 1943-1949.

Rose-Ped, A. M., Bellm, L. A., Epstein, J. B., Trotti, A., Gwede, C., \& Fuchs, H. J. (2002). Complications of radiation therapy for head and neck cancers. The patient's perspective. Cancer nursing, 25, 461-467; quiz 468-469.

Saunders, C. (1988). Spiritual pain. Journal of Palliative Care, 4, 29-32. 
Sawada, N. O., de Paula, J. M., Sonobe, H. M., Zago, M. M., Guerrero, G. P., \& Nicolussi, A. C. (2012). Depression, fatigue, and health-related quality of life in head and neck cancer patients: a prospective pilot study. Supportive care in cancer : official journal of the Multinational Association of Supportive Care in Cancer.

Saxena, S., \& Orley, J. (1997). Quality of life assessment: The world health organization perspective. European psychiatry : the journal of the Association of European Psychiatrists, 12S3, 263s-266s.

Smets, E. M., Garssen, B., Schuster-Uitterhoeve, A. L., \& de Haes, J. C. (1993). Fatigue in cancer patients. British journal of cancer, 68, 220-224.

Stajduhar, K. I., Thorne, S. E., McGuinness, L., \& Kim-Sing, C. (2010). Patient perceptions of helpful communication in the context of advanced cancer. Journal of Clinical Nursing, 19, 2039-2047.

Strang, P. (2007). Livsglädjen och det djupa allvaret : - om existentiell kris och välbefinnande. Stockholm: Natur och Kultur.

Trotti, A., Bellm, L. A., Epstein, J. B., Frame, D., Fuchs, H. J., Gwede, C. K., Komaroff, E., Nalysnyk, L., \& Zilberberg, M. D. (2003). Mucositis incidence, severity and associated outcomes in patients with head and neck cancer receiving radiotherapy with or without chemotherapy: a systematic literature review. Radiotherapy and oncology : journal of the European Society for Therapeutic Radiology and Oncology, 66, 253-262.

Velthuis, M. J., Agasi-Idenburg, S. C., Aufdemkampe, G., \& Wittink, H. M. (2010). The effect of physical exercise on cancer-related fatigue during cancer treatment: a meta-analysis of randomised controlled trials. Clinical oncology, 22, 208-221. 
Wong, P. C., Dodd, M. J., Miaskowski, C., Paul, S. M., Bank, K. A., Shiba, G. H., \& Facione, N. (2006). Mucositis pain induced by radiation therapy: prevalence, severity, and use of selfcare behaviors. Journal of pain and symptom management, 32, 27-37.

Yalom, I. D. (1980). Existential psychotherapy. New York: Basic Books. 
Table 1

Socio-demographic and medical characteristics in the 26

interviewed HNC patients

\begin{tabular}{|c|c|}
\hline & Patients \\
\hline Sex (female/male), $n$ & $7 / 19$ \\
\hline Age, yrs, mean, SD & $64 \pm 10$ \\
\hline Married or cohabiting/single,n, $(\%)$ & $20(77) / 6(23)$ \\
\hline Worked before RT, n (\%) & $10(38,5)$ \\
\hline Retired/unemployed ,n,(\%) & $13(50) / 3(11,5)$ \\
\hline \multicolumn{2}{|l|}{ Smoking, n (\%) } \\
\hline Non-smokers & $8(30,8)$ \\
\hline Smokers & $11(42,3)$ \\
\hline Ex-smokers & $7(26,9)$ \\
\hline \multicolumn{2}{|l|}{ Cancer site, $\mathrm{n},(\%)$} \\
\hline Oral cavity & $9(35)$ \\
\hline Pharynx & $9(35)$ \\
\hline Larynx & $4(15)$ \\
\hline Others & $4(15)$ \\
\hline \multicolumn{2}{|l|}{ Types of $H N C, n$} \\
\hline Base of tongue & 4 \\
\hline Buccal & 1 \\
\hline Epipharynx & 1 \\
\hline Gingiva & 3 \\
\hline Larynx & 4 \\
\hline Maxillary & 1 \\
\hline Metastasis secondary & 1 \\
\hline Mouth floor & 1 \\
\hline Palatal & 1 \\
\hline Parotid & 2 \\
\hline Tongue & 4 \\
\hline Tonsil & 3 \\
\hline \multicolumn{2}{|l|}{ TNM ${ }^{1}$, Classification of Malignant } \\
\hline \multicolumn{2}{|l|}{ Tumours, $\mathrm{n},(\%)$} \\
\hline I & $4(15)$ \\
\hline II & $6(23)$ \\
\hline III & $5(19)$ \\
\hline IIII & $11(42)$ \\
\hline \multicolumn{2}{|l|}{ Treatment, n, (\%) } \\
\hline RT & $10(38,5)$ \\
\hline RT/hyper fractioning & $5(19,2)$ \\
\hline $\mathrm{RT}+$ chemotherapy & $11(42,3)$ \\
\hline
\end{tabular}


Table 2

An overview of main category, categories and subcategories appearing in the interviews.

\begin{tabular}{|c|c|c|c|}
\hline \multicolumn{4}{|c|}{$\begin{array}{c}\text { The head and neck cancer patients did not experience that } \\
\text { the severe physical pain influenced the psychological } \\
\text { suffering but pain only influenced the social life }\end{array}$} \\
\hline $\begin{array}{l}\text { Pain in the } \\
\text { head and neck } \\
\text { region }\end{array}$ & $\begin{array}{l}\text { The } \\
\text { overwhelming } \\
\text { fatigue }\end{array}$ & $\begin{array}{l}\text { The altered } \\
\text { mood and } \\
\text { preoccupied } \\
\text { mind }\end{array}$ & $\begin{array}{l}\text { Decreased } \\
\text { participation } \\
\text { and changed } \\
\text { relations }\end{array}$ \\
\hline \multirow{8}{*}{$\begin{array}{l}\text { Oral cavity and } \\
\text { pharynx and its } \\
\text { consequences }\end{array}$} & Sleep disturbance & Altered feelings & Changed social \\
\hline & $\begin{array}{c}\text { Consequences in } \\
\text { daily activities }\end{array}$ & $\begin{array}{c}\text { Feelings of } \\
\text { mistrust }\end{array}$ & Nutrition barriers \\
\hline & Debility and & Depressed mood & Withdrawal \\
\hline & & Thoughts of death & $\begin{array}{l}\text { Changed } \\
\text { relations }\end{array}$ \\
\hline & & $\begin{array}{l}\text { Conquer the } \\
\text { illness }\end{array}$ & \\
\hline & & $\begin{array}{l}\text { Guilt and } \\
\text { unfairness }\end{array}$ & \\
\hline & & $\begin{array}{l}\text { Changed life } \\
\text { perspectives and } \\
\text { meaning of life }\end{array}$ & \\
\hline & & $\begin{array}{l}\text { Yearning of the } \\
\text { future }\end{array}$ & \\
\hline
\end{tabular}

